\title{
The alcohol dehydrogenase polymorphism of Drosophila melanogaster in relation to environmental ethanol, ethanol tolerance and alcohol dehydrogenase activity
}

\author{
J. B. Gibson and \\ A. V. Wilks
}

\author{
Population Genetics Group, Research School of \\ Biological Sciences, The Australian National \\ University, P.O. Box 475, Canberra City, A.C.T. 2601, \\ Australia.
}

Ethanol levels in Drosophila breeding sites were higher in a winery storing fortified wines than in nearby grape pressings or in orchard fruits. The relative abundance of $D$. simulans to $D$. melanogaster was negatively correlated with ethanol levels. In $D$. melanogaster there were no significant differences in $A_{d h^{F}}$ frequency between the orchard and winery populations. The ethanol tolerance of wild caught $D$. melanogaster males paralleled the levels of ethanol in the breeding sites but $A d h$ alleles and ethanol tolerance segregated largely independently of each other. Levels of ADH activity were positively associated with the ethanol tolerance of the different populations and with levels of ethanol in the breeding sites, but it is argued that the ethanol levels are not causative. Flies from inside the winery had higher ADH levels due mainly to greater amounts of ADH-F. The difference in activity persisted for at least one generation in the laboratory. After ten generations of laboratory culture the differences in ethanol tolerance were still present but there were no significant differences in ADH activity.

\section{INTRODUCTION}

The adaptive significance of enzyme polymorphisms in natural populations remains a controversial subject in the absence of unambiguous evidence for the mechanisms of selection (Hedrick et al., 1980). The alcohol dehydrogenase (ADH, EC 1.1.1.1.) polymorphism in Drosophila melanogaster provides a good example of these difficulties (see reviews in McDonald, 1983, and Zera et al., 1983).

Attempts to identify selective mechanisms maintaining the $A d h$ polymorphism have utilised laboratory experiments and field studies on natural populations (see reviews in Clarke, 1975; Gibson, 1982; Van Delden, 1983). The laboratory experiments, focussing on the effects on $A d h$ frequencies of variation in the concentration of a presumed ADH substrate, ethanol, have given conflicting results. Those single or multi-generation fitness experiments which used inbred lines, or material that had previously been maintained in the laboratory for a number of generations, generally showed that $A d h^{F}$ (which produces more ADH than $A d h^{S}$,
Gibson, 1972, Lewis and Gibson, 1978, Maroni, 1978, McDonald et al., 1980 and Maroni et al., 1982) increased in frequency in cultures maintained with media supplemented with ethanol greater than 6 per cent (v/v) (e.g., Gibson, 1970). These results have led some workers to argue that heterogeneity in ethanol levels is involved in the maintenance of the $A d h$ polymorphism. However, this argument is difficult to sustain in the face of results from similar experiments but using outbred, or freshly captured material, which have not demonstrated an increase in $A d h^{F}$ (see discussion in Gibson and Oakeshott, 1982, Oakeshott et al., 1984 and Barbancho et al., 1987). It has also been shown that artificial selection for increasing tolerance to ethanol in populations segregating $A d h$ alleles does not necessarily lead to an increase in $A d h^{F}$ frequency (Gibson et al., 1979).

Studies on natural populations comparing $A d h$ frequencies inside and outside buildings processing and storing wine, and hence habitats assumed to differ in ethanol levels, have also given conflicting results. McKenzie and Parsons (1972; 1974) found no differences in $A d h$ frequencies at 
Chateau Tahbilk in Victoria, Australia, and neither did Marks et al. (1980) at a Sonoma Valley winery in California, nor Gibson et al. (1981) at seven Australian wineries. But Briscoe et al. (1975) and Hickey and McLean (1980) reported significantly higher frequencies of $A d h^{F}$ inside wineries in Spain and Canada compared with habitats outside, and argued that the differences resulted from higher levels of ethanol inside wineries. This conclusion was not supported by data of Gibson et al. (1981) which showed that average ethanol concentrations in winery habitats (except those associated with fortified wines) did not exceed those found in decaying fruits and vegetables in orchards and gardens.

Some of the most consistent evidence for a relationship between ADH activity and ethanol tolerance derives from inter-specific comparisons. In particular $D$. simulans, with lower ADH levels than the $A d h^{S}$ homozygotes of $D$. melanogaster, has much lower ethanol tolerance and is rare inside wineries. Further Libion-Mannaert et al. (1976) and Parsons and Stanley (1981) have shown that the utilisation of ethanol as an energy source correlates with ADH activity within and between species and Ziolo and Parsons (1982) have argued that tolerance to ethanol is an ecologically significant phenotype of Drosophilids.

Interpretation of the data on the $A d h$ polymorphism in natural populations is made difficult because none of the studies have directly compared both the ethanol tolerance and the ADH activities of $A d h$ genotypes in populations exposed to different measured levels of ethanol. Thus the conflicting results could be explained by assuming, for example in cases where no differences in gene frequency were detected, that ethanol levels did not differ between habitats or that there were no differences in ADH activity between $A d h$ genotypes in natural populations.

To overcome these difficulties in elucidating the role of ethanol tolerance in the maintenance of the $A d h$ polymorphism we have investigated newly captured $D$. melanogaster and $D$. simulans from populations inhabitating environments with a range of ethanol levels from less than 1 per cent to more than 9 per cent.

\section{MATERIALS AND METHODS}

All of the experiments, except where otherwise stated, were carried out on newly captured flies from in and around the All Saints winery near Rutherglen, Victoria, Australia. The All Saints winery specialises in fortified wines (up to 20 per cent $\mathrm{v} / \mathrm{v}$ ethanol) which are stored above ground in oak casks. Part of the same building is used for the processing of wine and contains open fermentation vats. The flies were collected between February and April in 1981 and 1982 from the following four types of habitat:

(a) decaying fruits (mainly peaches, pears and plums) in an orchard approximately $6 \mathrm{~km}$ from the All Saints winery.

(b) dumps of grape skins (must) in the vineyard $400 \mathrm{~m}$ from the winery.

(c) the surface and edges of open fermentation vats sited just inside the winery but close to a large entrance.

(d) leakage from barrels containing fortified wines.

At all these sites flies were swept by net, or allowed to emerge from samples of the material in which they were breeding. In all respects investigated, flies obtained by these two methods of sampling gave consonant results.

Flies were maintained in the laboratory on standard media containing $10 \mathrm{~g}$ agar, $50 \mathrm{~g}$ glucose, $26 \mathrm{~g}$ sucrose, $50 \mathrm{~g}$ maize meal, $22 \cdot 5 \mathrm{~g}$ wheat germ and $6 \mathrm{~g}$ yeast made to 1 litre with water with $12.5 \mathrm{ml}$ of acid mix comprising 42 per cent proprionic acid and 4 per cent orthophosphoric acid.

The levels of ethanol were measured as previously described (Gibson et al., 1981) in samples taken from sites at which $D$. melanogaster had been shown to be breeding in each of the four types of habitat. The samples, each weighing approximately $1 \mathrm{~g}$, were put into scintillation vials which were immediately sealed with a rubber septum and then frozen in liquid nitrogen to prevent loss of ethanol. Ethanol levels were assayed by the "head space" method of Brien and Loomis (1978), in a Hewlett Packard gas chromatograph (Gibson et al., 1981).

Tolerance to ethanol was measured in each sex by keeping 17 cohorts, each of 20 flies, in $300 \mathrm{ml}$ culture bottles with $50 \mathrm{ml}$ of standard media containing 9 per cent $(\mathrm{v} / \mathrm{v})$ ethanol and scoring the number of flies alive after six days. This level of ethanol was used because laboratory experiments indicate that concentrations above 6 per cent $(\mathrm{v} / \mathrm{v})$ provide a metabolic cost to $D$. melanogaster (Parsons and Stanley, 1981) and, at least in inbred material, can lead to an increase in the frequency of $A d h^{F}$ (Van Delden, 1983). The flies used in these tests were collected on emergence from random samples of up to $200 \mathrm{ml}$ of material taken from breeding sites in each of the four types of 
habitat, and similar numbers of five to seven day old flies were used from each of the samples from a particular habitat. Extra flies from each habitat were typed for $A d h$ genotypes (see below) and these data are included in table 3 as the March 1981(a) samples.

Adh genotypes were scored after electrophoresis of single fly extracts on cellulose acetate membranes using the method described by Lewis and Gibson (1978). The frequency of a third allele $A d h^{F C h D}$ was also scored in the flies collected in 1981 and 1982 using the technique of Wilks et al. (1980). However, its frequency was always found to be less than 5 per cent in these populations and it was not scored in the ethanol tolerance experiments or in the single fly assays. The ADH electrophoresis patterns were used to distinguish $D$. simulans females (post mortem in the tolerance tests) from D. melanogaster; the males of the two species were classified by their external genitalia and sorted prior to the experiments. The 1981 and 1982 collections were also scored for sn-glycerol-3phosphate dehydrogenase (EC 1.1.1.8.) Gpdh genotypes after electrophoresis on cellulose acetate membranes (Gibson et al., 1986).

ADH activity was measured in crude homogenates of 20 male flies as previously described (Gibson et al., 1980). Unless otherwise stated the assays were made on flies collected in the wild from the four habitats. Assays were separately made with 2-propanol and ethanol as substrate but as there was a correlation of 0.93 between the two sets of activities we report the data obtained with 2-propanol. In some experiments $\mathrm{ADH}$ was assayed in single male flies also taken directly from the natural populations. For these assays each fly was weighed and put into a micro-centrifuge tube held in liquid nitrogen and then ground up by a perspex pestle shaped to fit the micro-centrifuge tube. Buffer was added to the frozen fly in proportion to its weight $(200 \mu \mathrm{l} / \mathrm{mg})$. The samples were centrifuged at $10,000 \mathrm{~g}$ for 3 mins and the supernatant was assayed for ADH (Gibson et al., 1980). The pellet was used to prepare a sample for the electrophoretic determination of the fly's $A d h$ genotype. In most cases the flies' ADH activities and tolerance were measured within $48 \mathrm{hrs}$ of capture during which time the flies were held on standard laboratory culture media.

The amount of ADH protein in crude extracts was assayed by radial immunodiffusion (Mancini et al., 1965) as modified by Lewis and Gibson (1978) and using the antisera they describe, which were produced in rabbits.

\section{RESULTS}

The ethanol levels detected in Drosophila breeding sites in the 1981 and 1982 samples are shown in table 1. There was significant heterogeneity in ethanol content between the four kinds of habitat in and around the All Saints winery. The highest mean level was found in leakages from barrels of fortified wines inside the winery $(3 \cdot 2 \pm 0.62$ per cent $\mathrm{v} / \mathrm{v})$ and this was significantly higher $\left(t_{52}=\right.$ $3.9, p<0.001)$ than the mean $(2 \cdot 3 \pm 0.72$ per cent $\mathrm{v} / \mathrm{v}$ ) in the fermentation vats inside the winery but close to an entrance. At breeding sites outside the winery the mean ethanol level was $1 \cdot 21 \pm 0 \cdot 67$ per cent $(\mathrm{v} / \mathrm{v})$ in grape pressings and $1 \cdot 62 \pm 0 \cdot 34$ per cent $(v / v)$ in the orchard. These values were not significantly different, but they were lower than the levels in the fermentation vats $\left(t_{53}=3 \cdot 7\right.$, $p<0.001)$.

$D$. simulans was at very low frequency in collections from inside the winery and was not found in the samples from the fermentation vats (table 2). The frequency was lower in the grape skin dump than in the orchard $\left(\chi_{1}^{2}=24.97, p<0.001\right)$. Nevertheless, $D$. simulans was found among flies that emerged from samples with a mean ethanol level of 5.84 per cent $(\mathrm{v} / \mathrm{v})$ (table 1$)$.

In D. melanogaster the proportion of female flies was higher in collections from inside the winery and at the fermentation vats and the excess was higher than at the grape skin dump $\left(\chi_{1}^{2}=13 \cdot 09\right.$, $p<0.001)$ which in turn was higher than at the orchard $\left(\chi_{1}^{2}=60 \cdot 1, \quad p<0 \cdot 001\right)$. In the $D$. melanogaster and $D$. simulans samples there was a higher frequency of males in the orchard collections. A similar distribution of $D$. melanogaster was reported by McKenzie (1974) at another Victorian winery, Chateau Tahbilk.

All samples of $D$. simulans were monomorphic for a single electrophoretically detectable $A d h$ allele and for a $G p d h$ allele, as was expected from other population surveys (Berger, 1970).

Three electrophoretically distinguishable alleles $\left(A d h^{F}, A d h^{F C h D}, A d h^{5}\right)$ were segregating at the $A d h$ locus in all the $D$. melanogaster samples (table 3 ). The frequency of $A d h^{F}$ varied between 0.65 and 0.69 but there was no evidence for heterogeneity in $A d h$ genotypes between any of the populations sampled in $1981\left(\mathrm{a}, \chi_{3}^{2}=0 \cdot 16, p>\right.$ $\left.0.05 ; \mathrm{b}, \chi_{2}^{2}=0.02, p>0.05\right)$ or in $1982\left(\chi_{3}^{2}=1 \cdot 14\right.$, $p>0.05)$.

In view of the evidence obtained by Cavener and Clegg $(1978,1981)$ that $A d h$ genotypes interact with $G p d h$ genotypes under high ethanol stress in 
Table 1 Levels of ethanol in D. melanogaster breeding sites. Those samples marked † include ones from which D. simulans also emerged; (a), (b) and (c) represent separate barrels of wine or separate piles of grape pressings

\begin{tabular}{|c|c|c|c|c|}
\hline \multirow[b]{2}{*}{ Type of habitat } & & \multirow[b]{2}{*}{$\begin{array}{l}\text { Number of } \\
\text { samples }\end{array}$} & \multicolumn{2}{|l|}{ Ethanol $(\% \mathrm{v} / \mathrm{v})$} \\
\hline & & & $\begin{array}{l}\text { Mean } \pm \\
\text { standard error }\end{array}$ & Range \\
\hline \multicolumn{5}{|l|}{$\begin{array}{l}\text { Inside winery, leakage } \\
\text { from barrel containing }\end{array}$} \\
\hline \multirow[t]{2}{*}{ muscat } & (a) & 2 & $4.49 \pm 0.05$ & $4 \cdot 41-4 \cdot 56$ \\
\hline & (b) & 5 & $5 \cdot 77 \pm 3 \cdot 01$ & $1 \cdot 15-9 \cdot 17$ \\
\hline \multirow[t]{3}{*}{ sherry } & (a) & 3 & $1 \cdot 30 \pm 0 \cdot 12$ & $1 \cdot 09-1 \cdot 51$ \\
\hline & (b) & 2 & $3 \cdot 22 \pm 0 \cdot 74$ & $1.96-4.47$ \\
\hline & (c) & 4 & $2 \cdot 33 \pm 1 \cdot 05$ & $0 \cdot 12-5 \cdot 06$ \\
\hline \multirow[t]{3}{*}{ port } & (a) & 3 & $2 \cdot 79 \pm 2 \cdot 43$ & $0.35-7 \cdot 64$ \\
\hline & (b) $\dagger$ & 8 & $4 \cdot 81 \pm 0 \cdot 86$ & $1 \cdot 63-7 \cdot 79$ \\
\hline & (c) $\dagger$ & 10 & $0.71 \pm 0.77$ & $0 \cdot 12-2 \cdot 52$ \\
\hline \multicolumn{5}{|l|}{ Open fermentation vats } \\
\hline \multirow[t]{3}{*}{ liquid in vat } & (a) & 2 & $2.54 \pm 0.06$ & $2 \cdot 48-2 \cdot 60$ \\
\hline & (b) & 2 & $4 \cdot 86 \pm 0 \cdot 31$ & $4 \cdot 55-5 \cdot 18$ \\
\hline & $(c) \dagger$ & 2 & $5 \cdot 84 \pm 0.06$ & $5 \cdot 78-5 \cdot 89$ \\
\hline \multirow[t]{2}{*}{ grape skins } & (a) & 2 & $2 \cdot 88 \pm 0 \cdot 10$ & $2 \cdot 78-2 \cdot 97$ \\
\hline & (b) $\dagger$ & 9 & $1 \cdot 46 \pm 0.95$ & $0-4 \cdot 26$ \\
\hline \multicolumn{5}{|c|}{ Outside winery } \\
\hline \multirow[t]{3}{*}{ discarded pressings } & (a) $\dagger$ & 4 & $0 \cdot 19 \pm 0 \cdot 01$ & $0-0.46$ \\
\hline & (b) $\dagger$ & 2 & $0.08 \pm 0.04$ & $0.03-0.14$ \\
\hline & (c) & 4 & $2 \cdot 88 \pm 2 \cdot 04$ & $1 \cdot 11-4 \cdot 65$ \\
\hline $\begin{array}{l}20 \mathrm{~cm} \text { under surface } \\
\text { of grape pressings }\end{array}$ & (c) & 8 & $1.89 \pm 1 \cdot 58$ & $0 \cdot 31-5 \cdot 45$ \\
\hline \multicolumn{5}{|l|}{ Orchard } \\
\hline pears & $\dagger$ & 6 & $1 \cdot 92 \pm 1 \cdot 31$ & $0 \cdot 23-3 \cdot 86$ \\
\hline \multirow[t]{2}{*}{ plums } & $\dagger$ & 14 & $1 \cdot 36 \pm 1 \cdot 52$ & $0-4 \cdot 35$ \\
\hline & Anal & of variance & & \\
\hline Source & $\mathrm{df}$ & M.S. & $\mathrm{F}$ & \\
\hline Between habitats & 3 & $16 \cdot 2$ & $4 \cdot 4^{* *}$ & \\
\hline Within habitats & 88 & $3 \cdot 7$ & & \\
\hline
\end{tabular}

$* * p<0.01$.

Table 2 Proportions of $D$. simulans and $D$. melanogaster and their sex ratios, $q / \delta$, in collections made in March 1982

\begin{tabular}{|c|c|c|c|c|}
\hline & \multicolumn{4}{|c|}{ All Saints } \\
\hline & Orchard & $\begin{array}{l}\text { Grape } \\
\text { skin dump }\end{array}$ & $\begin{array}{l}\text { Fermentation } \\
\text { vats }\end{array}$ & $\begin{array}{l}\text { Inside } \\
\text { winery }\end{array}$ \\
\hline Total flies scored & 830 & 620 & 522 & 560 \\
\hline Percentage $D$. simulans & $59 \cdot 1$ & $34 \cdot 1$ & non detected & $0 \cdot 3$ \\
\hline Sex ratio D. simulans & $0 \cdot 34^{*}$ & 0.54 & - & - \\
\hline Sex ratio $D$. melanogaster & $0 \cdot 28^{*}$ & 0.55 & $0.64^{*}$ & $0 \cdot 66^{*}$ \\
\hline
\end{tabular}

* Significantly different to $0.5, p<0.001$. 
Table 3 Adh allele frequencies in D. melanogaster in a Rutherglen orchard and at All Saints

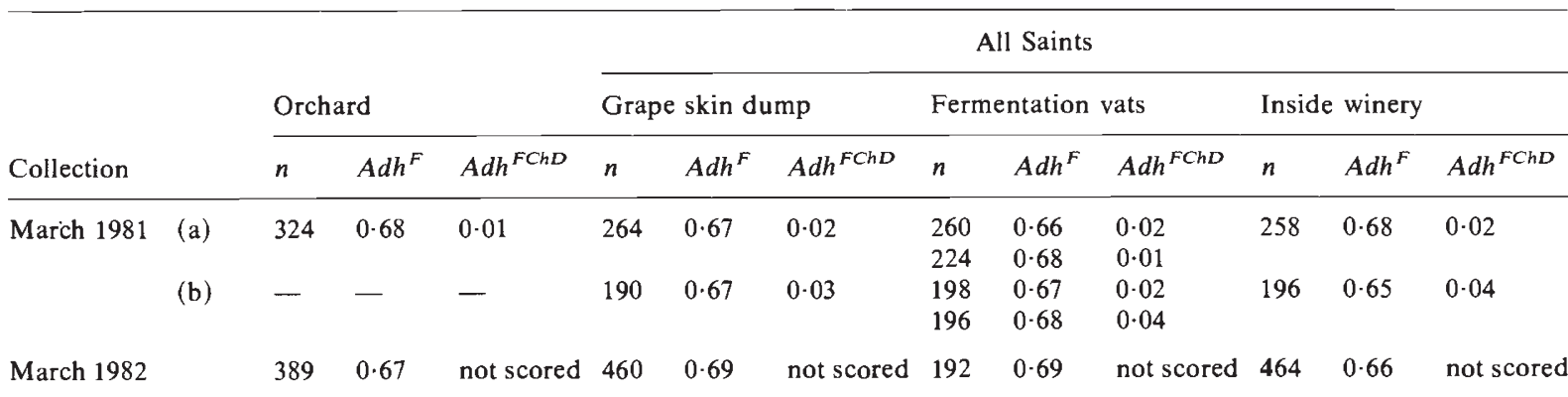

$n=$ number of genes scored.

laboratory experiments, Gpdh electrophoretically distinguishable alleles were scored in the flies, which were also scored for $A d h$, from the grape skin dump, the fermentation vats and the barrels. There was no heterogeneity in $G p d h$ frequency (mean $0.74 \pm 0.03)$ between sites $\left(\chi_{4}^{2}=4 \cdot 8, p>\right.$ $0.05)$ or any evidence of gametic disequilibrium with Adh alleles $(R=0.13, p>0.05)$, (Knibb, 1983).

Ethanol tolerance tests were carried out on flies from 26 of the breeding sites included in table 1. The average ethanol levels (per cent $\mathrm{v} / \mathrm{v}$ ) in these sites were, $1.64 \pm 0.28$ in ten samples from the orchard, $1 \cdot 26 \pm 0.68$ in four samples from the grape skin dump, $2 \cdot 17 \pm 0.71$ in four samples from around the edges of the fermentation vats and $3 \cdot 16 \pm 0.62$ in eight samples from separate leakages from barrels of fortified wine (between habitats, $\left.F_{3 / 22}=6 \cdot 2, p<0 \cdot 01\right)$. There was a significant difference in ethanol tolerance between habitats (table 4) although the flies from fermentation vats and inside the winery were similar $\left(t_{32}=0 \cdot 75, p>\right.$ $0.05)$ as were those from the grape pressings and the orchard $\left(t_{32}=1.3, p>0.05\right)$. The tolerances of male and female flies from inside the winery and from the fermentation vats were significantly higher than that of flies from the orchard and the grape skin dump (for males $t_{66}=4.3, p<0.001$, for females, $\left.t_{66}=4 \cdot 1, p<0.001\right)$. Overall there was no significant sex difference, nor sex $\times$ habitat interaction, in tolerance. A smaller study of ethanol tolerance carried out in the same way but using net caught flies from around the same breeding sites gave consonant results (between habitats, $\left.F_{3 / 42}=0.9, p<0.05\right)$.

Tolerance tests were also carried out on $D$. simulans collected in the orchard (insufficient flies were available from the other habitats). The average mortality was over 90 per cent using the same test conditions as for D. melanogaster.

Table 4 Mean ethanol tolerance (\% survival with standard errors in angles) in D. melanogaster collected at different breeding sites

\begin{tabular}{lllll}
\hline Sex & Orchard & $\begin{array}{l}\text { Grape skin } \\
\text { dump }\end{array}$ & $\begin{array}{l}\text { Fermentation } \\
\text { vats }\end{array}$ & $\begin{array}{l}\text { Inside } \\
\text { winery }\end{array}$ \\
\hline Males & $23 \cdot 2 \pm 1 \cdot 9$ & $24 \cdot 7 \pm 1 \cdot 6$ & $42 \cdot 1 \pm 1 \cdot 8$ & $54 \cdot 4 \pm 1 \cdot 8$ \\
Females & $33 \cdot 2 \pm 2 \cdot 2$ & $35 \cdot 0 \pm 2 \cdot 4$ & $36 \cdot 8 \pm 2 \cdot 2$ & $47 \cdot 3 \pm 1.9$ \\
\hline
\end{tabular}

Analysis of variance of angularly transformed data

\begin{tabular}{|c|c|c|c|c|}
\hline Source & $\mathrm{df}$ & M.S. & & $F$ \\
\hline Habitats & 3 & $1355 \cdot 9$ & & $8 \cdot 4^{* * *}$ \\
\hline Sex & 1 & $118 \cdot 6$ & $\left(F_{96 / 1}\right)$ & $1.4 \mathrm{~ns}$ \\
\hline Replicates & 16 & $56 \cdot 6$ & $\left(F_{96 / 16}\right)$ & $2 \cdot 8 \mathrm{~ns}$ \\
\hline Sex $\times$ Habitats & 3 & 318.9 & & $2 \cdot 0 \mathrm{~ns}$ \\
\hline Sex $\times$ Replicates & 16 & $53 \cdot 2$ & $\left(F_{96 / 16}\right)$ & $3 \cdot 0 \mathrm{~ns}$ \\
\hline Error & 96 & $161 \cdot 2$ & & \\
\hline Total & 135 & & & \\
\hline
\end{tabular}

*** $P<0-001$. 
In order to test for a differential effect of ethanol on survival of the D. melanogaster Adh genotypes all the male flies surviving after seven days in the ethanol tolerance tests, and a similar number from cohorts of male flies held on standard media for six days, were scored for Adh genotypes. As large samples of male flies (340) from each of the four habitats were initially placed on each type of media it was assumed that the initial $A d h$ gene frequency on standard and ethanol media were the same. These data (table 5) show that there are no significant differences in gene frequencies between survivors on ethanol and standard media, whether the tested flies came from inside or outside the winery. Thus ethanol tolerance of adult male flies is not associated with $A d h$ genotype in any of the four habitats.

In samples of male $D$. melanogaster caught in the wild and assayed within three days, there was significant heterogeneity in ADH activity between habitats (table 6), although activity was similar in flies from inside the winery and from the fermentation vats $\left(t_{8}=1.65, p>0.05\right)$ and between the grape skin dump and orchard samples $\left(t_{8}=0 \cdot 66\right.$, $p>0.05$ ); the significant difference was between samples from the winery and those from outside $\left(t_{18}=4 \cdot 12, p<0 \cdot 001\right)$. This heterogeneity in ADH activity was found again in samples taken from similar sites a year later in 1982 (table 6) although in these samples the overall mean activity was higher than in 1981.

The 1981 and 1982 wild caught $D$. melanogaster samples from the orchard, grape skin dump, fermentation vats and inside the winery were scored for the amount of ADH protein. There was a correlation of 0.89 between ADH activity and the amount of ADH protein. In analyses of variance of these data both the differences between habitats $\left(F_{3 / 32}=18 \cdot 7, p<0.001\right)$ and between years $\left(F_{1 / 32}=\right.$ $10 \cdot 2, p<0 \cdot 001)$ were significant.

From each of the four sites five cultures of 40 females from the 1981 samples were maintained on standard laboratory food for one generation, then samples of $F_{1}$ male flies (6-8 days from emergence) were assayed for ADH activity. These data (table 6) show that the differences in ADH activity between the wild caught flies from the four habitats persist in the progenies cultured in the laboratory. The amount of ADH protein also differed between the habitats $\left(F_{3 / 16}=8.6, p<0.01\right)$.

Further assays of ADH activity and of ethanol tolerance were made when the flies collected on the grape pressings and from the barrel leakages had been maintained for ten generations on standard laboratory media at $22^{\circ} \mathrm{C}$. Five separate cultures were maintained and assayed from each of the two habitats. In these tests the flies derived from collections around leaking barrels remained more tolerant to ethanol $\left(t_{8}=6 \cdot 5, p<0 \cdot 001\right)$ than those from the grape pressings (table 7) but the tolerances were less than the levels observed in newly captured material (grape skin dump $t_{8}=3 \cdot 1$, $p<0 \cdot 005$; inside the winery $t_{8}=2 \cdot 6, p<0 \cdot 05$ ). It is noteworthy that the frequencies of $A d h^{F}$ had not diverged significantly either in the two set of cultures $\left(\chi_{1}^{2},=0 \cdot 36, p>0.05\right)$ or from the frequencies observed in wild caught material $\left(\chi_{1}^{2},=0 \cdot 36\right.$, $p>0.05$ ) (cf. tables 3 and 7).

Samples of $D$. simulans males from the orchard and from the grape pressings were assayed for ADH (insufficient flies were available from the collections at the other sites). These data (table 6) show that ADH activity in D. simulans is about a fifth of that in the D. melanogaster orchard population. It is interesting that $D$. simulans from the grape pressings have significantly higher $\mathrm{ADH}$ activity $\left(t_{4}=2.8, p<0.05\right)$ than those from the orchard, and significantly higher amounts of ADH protein $\left(i_{4}=2.9, p<0.05\right)$ as measured using the antiserum prepared against $D$. melanogaster ADH.

To test whether there were significant differences in ADH activity between flies of the different $A d h$ genotypes one hundred $D$. melanogaster male flies collected around barrel leakages and a hundred collected from the grape pressings were assayed individually for ADH activity and scored

Table 5 Distribution of $A d h$ genotypes among male flies surviving after seven days on standard media and on $9 \%$ ethanol media

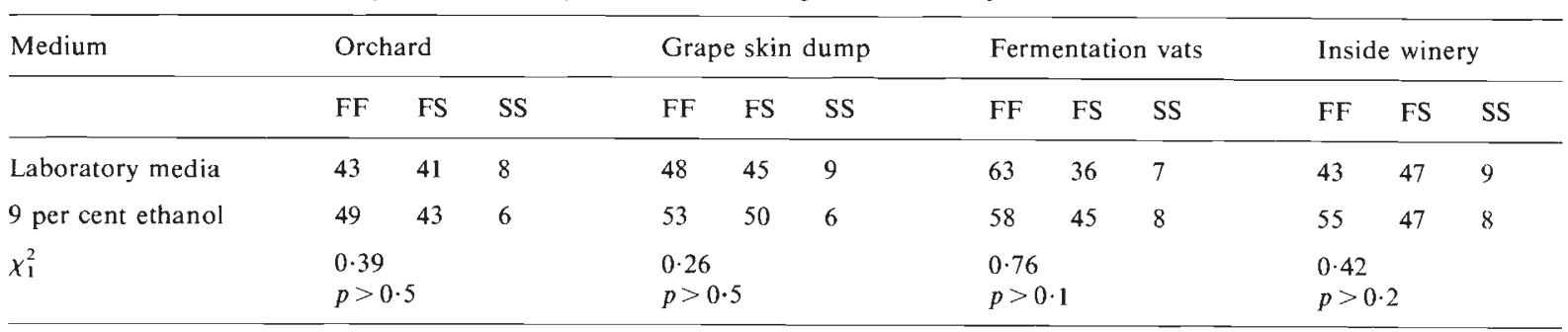


Table 6 Alcohol dehydrogenase activity (units/mg live weight) in male flies \pm standard errors. For the $D$. melanogaster samples five (and for the $D$. simulans samples three) separately prepared extracts were assayed from each habitat. One unit of ADH activity is defined as an increase in absorbance at $340 \mathrm{~nm}$ of $0.001 / \mathrm{min}$ (equivalent to $1.61 \times 10^{-4}$ moles $\mathrm{NADH}$ produced per $\mathrm{min}$ )

\begin{tabular}{lllll}
\hline Collection & Orchard & $\begin{array}{l}\text { Grape } \\
\text { skin dump }\end{array}$ & $\begin{array}{l}\text { Fermentation } \\
\text { vats }\end{array}$ & $\begin{array}{l}\text { Inside } \\
\text { winery }\end{array}$ \\
\hline $\begin{array}{l}\text { D. melanogaster } \\
1981 \text { wild caught }\end{array}$ & $140 \cdot 2 \pm 4 \cdot 9$ & $136 \cdot 2 \pm 3 \cdot 6$ & $152 \cdot 4 \pm 8 \cdot 9$ & $168 \cdot 7 \pm 4 \cdot 3$ \\
$\begin{array}{l}1981 \text { laboratory reared } \\
\text { one generation }\end{array}$ & $141 \cdot 1 \pm 5 \cdot 2$ & $133 \cdot 7 \pm 2 \cdot 7$ & $148 \cdot 5 \pm 3 \cdot 5$ & $163 \cdot 8 \pm 3 \cdot 8$ \\
$\begin{array}{l}1982 \text { wild caught } \\
\begin{array}{l}\text { D. simulans } \\
1982 \text { wild caught }\end{array}\end{array}$ & $149 \cdot 3 \pm 4 \cdot 7$ & $145 \cdot 1 \pm 3 \cdot 9$ & $163 \cdot 7 \pm 5 \cdot 0$ & $208 \cdot 2 \pm 3 \cdot 6$ \\
& $29 \cdot 2$ & $38 \cdot 1$ & - & - \\
\hline
\end{tabular}

Analysis of variance

\begin{tabular}{lrrr}
\hline Source & df & M.S. & \multicolumn{1}{l}{$F$} \\
\hline (a) Wild caught flies & & & \\
Habitats & 3 & 4735 & $19 \cdot 5^{* * *}$ \\
years & 1 & 2706 & $11 \cdot 1^{* *}$ \\
Habitats $\times$ years & 3 & 624 & $2 \cdot 6 \mathrm{~ns}$ \\
Error & 32 & 243 & \\
(b) Laboratory reared flies & 3 & & \\
Habitats & 16 & 980 & $8 \cdot 8^{* *}$ \\
Error & 112 & \\
\hline
\end{tabular}

$* * p<0.01$.

$* * * p<0.001$.

for ADH electrophoretic phenotype. Four points emerge from the results of these assays (table 8 ). First, $A d h$ genotype frequencies do not differ significantly between sites $\left(\chi_{2}^{2},=0.74, p>0 \cdot 05\right)$; second, segregation of electrophoretically distinguishable alleles at the $A d h$ locus accounts for the vast majority of variation in $\mathrm{ADH}$ activity as there is virtually no overlap in $\mathrm{ADH}$ activity between the three $A d h$ genotypes (see also Anderson and Gibson, 1985). Third, there is a significant difference in ADH activity between flies from the two types of habitat. Fourth, although the habi-

Table 7 ADH activity and tolerance ( \pm standard errors) to ethanol of male flies from the 1981 samples maintained for ten generations in the laboratory on standard media. Each value is the mean obtained from extracts of five separate cultures

\begin{tabular}{lcc}
\hline & $\begin{array}{l}\text { Grape skin } \\
\text { dump }\end{array}$ & Inside winery \\
\hline ADH activity & $140 \cdot 5 \pm 4 \cdot 6$ & $146 \cdot 2 \pm 7.7$ \\
$\begin{array}{l}\text { Ethanol tolerance } \\
(\% \text { surviving })\end{array}$ & $15 \cdot 4 \pm 1.4$ & $36 \cdot 5 \pm 2 \cdot 1$ \\
$A d h^{F}$ frequency & $0 \cdot 71 \pm 0.05$ & $0.69 \pm 0.07$ \\
\hline
\end{tabular}

tats $\times$ genotype interaction is not significant inspection of the data (table 8) shows that the $A d h^{F}$ homozygotes from inside the winery have significantly higher activity than $A d h^{F}$ homozygotes from the grape skin dump $\left(t_{92}=2 \cdot 9, p<0.01\right)$.

Table 8 Alcohol dehydrogenase activities, with standard errors, in assays of single male flies (sample sizes in parentheses)

\begin{tabular}{llll}
\hline \multirow{2}{*}{ Source of flies } & \multirow{2}{*}{ Adh } & \multicolumn{2}{l}{ Genotypes } \\
& FF & FS & SS \\
\hline Inside winery & $189 \pm 5 \cdot 1$ & $113 \pm 4 \cdot 5$ & $57 \pm 5 \cdot 5$ \\
& $(49)$ & $(42)$ & $(9)$ \\
Grape skin dump & $166 \pm 6 \cdot 3$ & $114 \pm 4 \cdot 4$ & $56 \pm 3 \cdot 3$ \\
& $(46)$ & $(45)$ & $(9)$ \\
\hline
\end{tabular}

Analysis of variance

\begin{tabular}{lrrr}
\hline Source & df & M.S. & \multicolumn{1}{c}{$F$} \\
\hline Habitats & 1 & 7,509 & \multicolumn{1}{c}{$4 \cdot 5^{*}$} \\
Adh genotypes & 2 & 155,838 & $92 \cdot 3^{* * *}$ \\
Habitats $\times$ genotypes & 2 & 3,482 & $2 \cdot 1 \mathrm{~ns}$ \\
Error & 194 & & \\
\hline
\end{tabular}

\footnotetext{
$* p<0 \cdot 05$.

$* * * \quad p<0.001$.
} 
There are no significant differences in activity between either the $A d h^{S}$ homozygotes $\left(t_{16}=0 \cdot 17\right.$, $p>0.05)$ or between the $A d h^{F} / A d h^{S}$ heterozygotes $\left(t_{85}=0 \cdot 18, p>0.05\right)$ from the two habitats. (We have found that the mean ADH activity in single fly assays is consistently lower than the value obtained from mass homogenates, possibly due to the differences in sample preparation). There was insufficient material remaining in these single fly extracts to measure the amounts of ADH protein, but in tests on similar samples there was a correlation of 0.84 between ADH protein amount and $\mathrm{ADH}$ activity in single fly assays.

In view of these results the ADH activities of flies which survive ethanol tolerance tests were investigated and compared with the activities of flies kept on control (standard) media. Extracts were made from four sets of 20 male flies taken from flies held on control media and from the survivors of the ethanol tolerance tests on samples from the grape skin dump and from inside the winery. These data (table 9) show that there is no significant difference in ADH activity in flies from the grape skin dump $\left(t_{6}=0.54, p>0.05\right)$ or from inside the winery $\left(t_{6}=0.61, p>0.05\right)$ compared with those kept on control media for six days. This shows that flies of any $A d h$ genotype with higher than average ADH activity do not have higher than average survival in the tolerance tests. It also indicates that $\mathrm{ADH}$ activity in adult flies is not increased by exposing the flies to 9 per cent ethanol media for six days.

Table 9 ADH activities ( \pm standard errors) in four separate assays of extracts of male flies from the grape skin dump and inside the winery which survive the tolerance tests or have been held on control media. Four separate extracts were assayed from each condition

\begin{tabular}{lll}
\hline & & ADH activity \\
\cline { 2 - 3 } Source of flies & Ethanol media & Control media \\
\hline Inside winery & $170 \cdot 2 \pm 5.6$ & $167.9 \pm 4.3$ \\
Grape skin dump & $138 \cdot 4 \pm 3 \cdot 7$ & $141 \cdot 5 \pm 3.9$ \\
\hline
\end{tabular}

\section{DISCUSSION}

The data described here focus on natural populations of $D$. melanogaster and $D$. simulans which feed and breed in habitats heterogeneous for ethanol levels up to 9 per cent $(\mathrm{v} / \mathrm{v})$. The habitats compared therefore provide a range of ethanol environments to which genetic adaptation might occur. It is important to emphasise that the ethanol levels in some of these breeding sites are not dissimilar to those which have been used in media in laboratory cultures and in which increases over generations in the frequency of $A d h^{F}$, relative to $A d h^{S}$, have been reported (for reviews of these experiments see Gibson and Oakeshott (1982) and Van Delden (1983)).

Two observations support the notion that the Drosophila populations investigated in this study have adapted to the different environments. First, and most importantly, there is the evidence that in the wild caught $D$. melanogaster the extent of tolerance to 9 per cent ethanol in the media parallels the levels of ethanol detected in the natural breeding sites from which the flies were collected.

Second, the relative abundance of $D$. simulans, which is very much less tolerant to ethanol than D. melanogaster (Parsons and Stanley, 1981), is lower at breeding sites inside the winery which have relatively high levels of ethanol compared to sites outside. Distributions similar to this have been reported before (McKenzie, 1974; Marks et al., 1980; Gibson et al., 1981); however the causative role of ethanol levels has been questioned, and other factors associated with buildings might be involved (David, 1979; Rouault and David, 1982). In the present study $D$. simulans were collected from habitats with more than 5.7 per cent $(\mathrm{v} / \mathrm{v})$ ethanol, which is higher than the average level in leakages from barrels, so that ethanol levels per se may not be responsible for the virtual exclusion of $D$. simulans from the winery habitats.

The adult sex ratio differences observed between the winery and orchard samples of $D$. melanogaster, and which have been reported in previous studies of winery habitats (McKenzie, 1974), are not due to sex differences in ethanol tolerance and remain unexplained. It will be informative in future work to compare the sex ratio at emergence with the sex ratio in net caught adults in each type of habitat.

Turning to the genetic consequences in $D$. melanogaster of adaptation to different ethanol levels, the evidence shows that changes in the frequencies of $A d h$ alleles are not involved. In agreement with three other studies (McKenzie and McKechnie, 1978; Marks et al., 1980; Gibson et al., 1981) the data for All Saints show that the distribution of $A d h$ alleles and genotypes in $D$. melanogaster was homogeneous over all collections, whether taken inside or outside the winery. Contrary results were reported by Briscoe et al. 
(1975) who observed significantly lower frequencies of $A d h^{F}$ on a rubbish dump $1 \mathrm{~km}$ from a wine cellar in Spain, and by Hickey and McLean (1980) who found significantly lower $A d h^{F}$ frequencies at sites more than $3 \mathrm{~km}$ from a Canadian winery. Hickey and McLean (1980) argued that sampling range might explain the differences between the data of Briscoe et al. (1975) and those of McKenzie and McKechnie (1978). However the present data, together with those described by Gibson et al. (1981), do not support this idea as the sites sampled encompass as wide a range of distances between winery and non-winery sites as the previous studies. Briscoe et al. (1975) reported that $D$. melanogaster were breeding in mats covering storage casks containing sherry with "12-15 per cent ethanol". However no other data on ethanol levels were given and it is possible that they were similar to those measured from leaking barrels of sherry at All Saints. It thus seems unlikely that levels of ethanol are implicated in the differences between the studies, although it remains possible that the mode of exposure to ethanol was important in bringing about the variation in $A d h^{F}$ frequencies (Oakeshott and Gibson, 1981).

Our direct evidence from tests of the relative fitness of $A d h$ genotypes in wild caught flies kept on 9 per cent ethanol media compared with those on standard media supports the gene and genotype frequency distributions observed in the All Saints habitats. Despite the high mortalities which occurred in these tests there were no significant differences in $A d h^{F}$ frequency between survivors on ethanol media and those on standard media. Further, the survivors on ethanol media did not have higher ADH activity. Thus it seems clear that tolerance to 9 per cent ethanol in these wild caught flies, whether they are from inside or outside the winery, is independent of allozyme variants at the $A d h$ locus. This result agrees with the observations of McKenzie and Parsons (1972) who investigated the genetic basis of ethanol tolerance in flies from the Chateau Tahbilk winery and found that variation at the $A d h$ locus contributed little to variation in ethanol tolerance. It remains possible that flies are occasionally exposed to ethanol levels (above 9 per cent) which do impose measureable selective differences. However any effects of such sporadic selection on $A d h$ frequencies would be unlikely to persist.

If variation at the $A d h$ locus has only a minor role in adaptation to ethanol, then the evidence that ADH activity varies between habitats is intriguing. Between the four breeding sites of $D$. melanogaster, ethanol levels, ethanol tolerance and
ADH activity are positively associated, although, within the population of each type of habitat, ethanol tolerance is independent of $A d h$ genotype and of variation in ADH activity. These data do not rule out a role of $\mathrm{ADH}$ in ethanol tolerance but they show that the within population variation in $\mathrm{ADH}$ is not important for tolerance in $D$. melanogaster.

There is evidence from other studies for modifiers of $\mathrm{ADH}$ activity in $D$. melanogaster either linked or unlinked to the $A d h$ locus (Ward and Hebert, 1972; Ayala and McDonald, 1980; Maroni et al., 1982; Maroni and Laurie-Ahlberg, 1983 ) but in the present data, and in other populations studied (Anderson and Gibson, 1985), the main cause of the variation in ADH activity is differences among the three $A d h$ genotypes. Thus our observation that ethanol tolerance is independent of segregation at the $A d h$ locus within each population suggests that the association of differences in ADH activity and in ethanol tolerance between populations are not causally related. It remains possible that any variation in $\mathrm{ADH}$ activity due to modifier genes or environmental induction might have different physiological effects. For example modifiers may cause ADH to be expressed with a different tissue distribution which might have larger effects on tolerance than variation in level within the same tissue (Clarke and Whitehead, 1984).

Our conclusion that variation in ADH activity and ethanol tolerance are not causally related in this material is at variance with evidence derived from studies of inbred laboratory lines (Morgan, 1974; Thompson and Kaiser, 1977). Nevertheless it is in agreement with the more relevant data on ADH activity in lines selected for ethanol tolerance (Gibson et al., 1979) which showed that no change in activity accompanied successful selection for ethanol tolerance.

The causes of the ADH activity differences between flies from different breeding sites are being investigated but four points must be taken into account in any explanation. First, although the differences in activity in $D$. melanogaster persisted after one generation of culture on standard laboratory media they were not detectable after 10 generations. Second, after 10 generations the association between ADH activity and ethanol tolerance in D. melanogaster was lost and only the differences in tolerance persisted. Third, the higher ADH activity in $D$. melanogaster from the barrel leakages compared with flies from the grape dump seems to be mainly ascribable to the activities of $A d h^{F} / A d h^{F}$ homozygotes although this does not 
completely account for the difference observed in assays of segregating cultures. Fourth, the ADH activities of $D$. simulans from the grape pressings are higher than those from the orchard collections even though our evidence shows that these two types of habitat do not differ significantly in ethanol levels.

Taken together these observations might be explained if there was genetic heterogeneity between breeding sites for electrophoretically cryptic Adh alleles, or modifiers, encoding different amounts of ADH. The electrophoretically cryptic allele $A d h^{F C h D}$ occurs at a frequency of less than 5 per cent in the All Saints populations and there is no evidence for heterogeneity between habitats. Studies comparing ADH activities in lines homozygous for four $A d h^{F C h D}$ alleles extracted from inside the winery with four alleles extracted from the grape skin dump have shown no significant difference in activity $\left(t_{6}=1 \cdot 3, p>0 \cdot 05\right)$. It thus seems unlikely that $A d h^{F C h D}$ contributes to the differences in activity between the habitats.

We have no quantitative data on the movement of flies between different parts of the winery but there are no obvious barriers to migration between the grape skin dumps, the fermentation vats close to the entrance to the winery and the wine storage barrels inside. Indeed, during the vintage period there is a daily traffic of grapes from the vineyard to the pressers just outside the winery building, and of must out to the dumps in the vineyard. However, the evidence that differences in ADH activity persist for at least one generation of laboratory culture suggests that migration between the winery habitats is in some way restricted, or alternatively, selective.

Other than in levels of ethanol, the orchard, grape pressings and winery breeding sites of $D$. melanogaster are likely to differ in the quantities and types of yeast and bacteria as well as in the concentrations of other nutrients. Clarke et al. (1979) demonstrated that the amount of yeast in laboratory cultures had large effects on $\mathrm{ADH}$ activity, and other substances likely to be present in natural habitats also affect ADH activity (Schwartz and Sofer, 1976; Papel et al., 1979). McKechnie and Geer (1984) have shown that in axenic cultures with 0.5 per cent $(\mathrm{w} / \mathrm{v})$ sugar, relatively low concentrations of ethanol $(2.5$ per cent $(\mathrm{v} / \mathrm{v}))$ give rise to two-fold increases in larval ADH activity, at least in the $A d h^{S}$ line with which they worked. Whatever the cause of the activity differences in the All Saints populations, the evidence is suggestive of differential regulation of $A d h^{F}$ and $A d h^{S}$ alleles, although it is surprising that the
$A d h^{F} / A d h^{S}$ heterozygote shows no effect. It will be important to test whether the same effect occurs in third instar larvae.

The data described in this paper, although demonstrating heterogeneity in ADH activity between wild caught male flies from different habitats, provide no evidence that ADH level per se in adults is an adaptive phenotype of the $A d h$ locus. Middleton and Kacser (1983) have shown that in vitro measurements of $\mathrm{ADH}$ are poor predictors of the in vivo physiological consequences of enzyme variation. They conclude that in vitro differences in ADH activity between $A d h^{F} / A d h^{F}$ and $A d h^{S} / A d h^{S}$ homozygotes are unlikely to contribute to fitness differences between genotypes, at least in so far as ethanol metabolism is concerned.

Our observations support their conclusions by showing that the $A d h$ polymorphism is unperturbed by environmental heterogeneity in ethanol levels. However, D. melanogaster populations do adapt to habitats with different levels of ethanol by some mechanism of tolerance, apparently unrelated to the variation in $\mathrm{ADH}$ activity.

Acknowledgements We thank Doug Anderson, Anh Cao, Tom May and the owners and staff of All Saints for their help in collecting Drosophila. The manuscript benefitted from the comments of reviewers and numerous colleagues.

\section{REFERENCES}

ANDERSON, D. AND GIBSON, J. B. 1985. Variation in alcohol dehydrogenase activity in vitro in flies from natural populations of Drosophila melanogaster. Genetica, 67, 13-19.

AYALA, F. J. AND McDONALD, J. F. 1980. Continuous variations: possible role of regulatory genes. Genetica, 52, 1-15.

BARBANCHO, M., SĂNCHEZ-CĂNETE, F. J. S., DORADO, G. AND PINEDA, M. 1987. Relation between tolerance to ethanol and alcohol dehydrogenase (ADH) activity in Drosophila melanogaster: Selection, genotype and sex effects. Heredity, $58,443-450$.

BERGER, E. M. 1970. A comparison of gene-enzyme variation between Drosophila melanogaster and D. simulans. Genetics, 66, 677-683.

BRIEN, J. F. AND LOOMIS, C. W. 1978. Gas-liquid chromatographic determination of ethanol and acetaldehyde in blood. Clin. Chim. Acta., 87, 175-180.

BRISCOE, D. A., ROBERTSON, A. AND MALPICA, J. 1975. Dominance of $A d h$ locus in response of adult Drosophila melanogaster to environmental alcohol. Nature, 255, 248249.

CAVENER, D. R. AND CLEGG, M. T. 1978. Dynamics of correlated genetic systems. IV. Multi-locus effects of ethanol stress environments. Genetics, 90, 629-644.

CAVENER, D. R. AND CLEGG, M. T. 1981. Multigenic response to ethanol in Drosophila melanogaster. Evolution, 35, 1-10.

CLARKE, B. 1975. The contribution of ecological genetics to evolutionary theory: detecting the direct effects of natural selection on particular polymorphic loci. Genetics, 79, 101113. 
CLARKE, B., CAMFIELD, R. G., GALVIN, A. M. AND PITS, C. R. 1979. Environmental factors affecting the quantity of alcohol dehydrogenase in Drosophila melanogaster. Nature, 280, 517-518.

CLARKE, B. AND WHITEHEAD, D. L. 1984. Opportunities for natural selection on DNA and protein at the $A d h$ locus in Drosophila melanogaster. Dev. Genet., 4, 425-438.

DAVID, J. R. 1979. Attractive behavior toward human constructions helps to explain the domestic and cosmopolitan status of some Drosophilids. Experientia, 35, 1436-1437.

GIBSON, J. B. 1970. Enzyme flexibility in Drosophila melanogaster. Nature, 227, 959-961.

GIBSON, J. B. 1972. Differences in the number of molecules produced by two allelic electrophoretic enzyme variants in Drosophila melanogaster. Experientia, 28, 975-976.

GIBSON, J. B. 1982. The alcohol dehydrogenase polymorphism in Drosophila melanogaster: patterns of variation for three alleles. In Lakovaara S. (ed.) Advances in Genetics, Development, and Evolution of Drosophila, Plenum, New York, pp. 273-284.

GIBSON, J. B., LEWIS, N., ADENA, M. A. AND WILSON, S. R. 1979. Selection for ethanol tolerance in two populations of Drosophila melanogaster segregating alcohol dehydrogenase allozymes. Aust. J. Biol. Sci., 32, 387-398.

GIBSON, J. B., CHAMBERS, G. K., WILKS, A. V. AND OAKESHOTT, J. G. 1980. An electrophoretically cryptic alcohol dehydrogenase variant in Drosophila melanogaster; I. Activity ratios, thermostability, genetic localisation and comparison with two other thermostable variants. Aust. $J$. Biol. Sci, 33, 479-489.

GIBSON, J. B., MAY, T. W. AND WILKS, A. V. 1981. Genetic variation at the alcohol dehydrogenase locus in Drosophila melanogaster in relation to environmental variation: ethanol levels in breeding sites and allozyme frequencies. Oecologia (Berlin), 51, 191-198.

GIBSON, J. B. AND OAKESHOTT, J. G. 1982. Tests of the adaptive significance of the alcohol dehydrogenase polymorphism in Drosophila melanogaster: paths, pitfalls and prospects. In Barker, J. S. F. and Starmer, W. T. (eds.) Ecological Genetics and Evolution. The Cactus-YeastDrosophila Model System, Academic Press, New York, pp. 291-306.

GIBSON, J. B., WILKS, A. V., CAO, A. AND FREETH, A. L. 1986. Dominance for sn-glycerol-3-phosphate dehydrogenase activity in Drosophila melanogaster: Evidence for differential allelic expression mediated via a trans-acting effect. Heredity, 56, 227-235.

HEDRICK, P. W., GINEVAN, M. R. AND EWING, E. P. 1976. Genetic polymorphism in heterogeneous environments. Ann. Rev. Ecol. Syst., 7, 1-32.

HICKEY, D. A. AND McLEAN, M. D. 1980. Selection for ethanol tolerance and $A d h$ allozymes in natural populations of Drosophila melanogaster. Genet. Res., 36, 11-15.

KNIBB, W. R. 1983. Chromosome inversion polymorphism in Drosophila melanogaster: III. Gametic disequilibrium and the contributions of inversion clines to the $A d h$ and Gpdh allozyme clines in Australasia. Genetica, 61, 139-146.

LEWIS, N. AND GIBSON, J. B. 1978. Enzyme protein amount variation in natural populations. Biochem. Genet., 16, 159170.

LIBION-MANNAERT, M., DELCOUR, J., DELTOMBE-LIETART, M. D., LENELLE-MONTFORT, N. AND ELENS, A. 1976. Ethanol as a "food" for Drosophila melanogaster: influence of the ebony gene. Experientia, 32, 22-23.

MANCINI, G., CARBONARA, A. O. AND HEREMANS, J. F. 1965. Immunochemical quantitation of antigens by single radial immunodiffusion. Immunochemistry, 2, 235-246.
MARKS, R. W., BRITTNASCHER, J. G., MCDONALD, J. F., PROUT, T. AND AYAla, F. J. 1980. Wineries, Drosophila, alcohol, and Adh. Oecologia (Berlin), 47, 141-144.

MARONI, G. 1978. Genetic control of alcohol dehydrogenase levels in Drosophila. Biochem. Genet., 16, 509-523.

MARONI, G., LAURIE-AHLBERG, C. C., ADAMS, D. A. AND WILTON, A. N. 1982. Genetic variation in the expression of ADH in Drosophila melanogaster. Genetics, 101, 431446.

MARONI, G. AND LAURIE-AHHLBERG, C. C. 1983. Genetic control of ADH expression in Drosophila melanogaster. Genetics, 105, 921-933.

McDONALD, J. F. 1983. The molecular basis of adaptation: a critical review of relevant ideas and observations. Ann. Rev. Ecol. Syst., 14, 77-102.

McDONALD, J. F., ANDERSON, S. M. AND SANTOS, M. 1980. Biochemical differences between products of the Adh locus in Drosophila. Genetics, 95, 1013-1022.

McKECHNIE, S. W. AND GEER, B. W. 1984. Regulation of alcohol dehydrogenase in Drosophila melanogaster by dietary alcohol and carbohydrate. Insect Biochem., 14, 231-242.

McKENZIE, J. A. 1974. The distribution of vineyard populations of Drosophila melanogaster and Drosophila simulans during vintage and non-vintage periods. Oecologia (Berlin), 15, $1-16$.

McKENZIE, J. A. AND McKECHNIE, w. W. 1978. Ethanol tolerance and the $A d h$ polymorphism in a natural population of Drosophila melanogaster. Nature, 272, 75-76.

McKENZIE, J. A. AND PARSONS, P. A. 1972. Alcohol tolerance: an ecological parameter in the relative success of Drosophila melanogaster and Drosophila simulans. Oecologia (Berlin), 10, 373-388.

McKENZIE, J. A. AND PARSONS, P. A. 1974. Microdifferentiation in a natural population of Drosophila melanogaster to alcohol in the environment. Genetics, 77, 385-394.

MORGAN, P. 1974. Selection acting directly on an enzyme polymorphism. Heredity, 34, 124-127.

MIDDLETON, R. J. AND KACSER, H. 1983. Enzyme variation, metabolic flux and fitness: alcohol dehydrogenase in Drosophila melanogaster. Genetics, 105, 633-650.

OAKESHOTT, J. G. AND GIBSON, J. B. 1981. Is there selection by environmental ethanol on the alcohol dehydrogenase locus in Drosophila melanogaster? In Gibson, J. B. and Oakeshott, J. G. (eds) Genetic Studies of Drosophila Populations, Australian National University Press, Canberra, pp. $103-120$.

OAKESHOTT, J. G., GIBSON, J. B. AND WILSON, S. R. 1984. Selective effects of the genetic background and ethanol on the alcohol dehydrogenase polymorphism in Drosophila melanogaster. Heredity, 53, 51-67.

PAPEL, J., HENDERSON, M., VAN HERREWEGE, J., DAVID, J. AND SOFER, W. 1979. Drosophila alcohol dehydrogenase activity in vitro and in vivo: effects of acetone feeding. Biochem. Genet., 17, 553-563.

PARSONS, P. A. AND STANLEY, S. M. 1981. Comparative effects of environmental ethanol on Drosophila melanogaster and $D$. simulans adults, including geographic differences in $D$. melanogaster. In Gibson, J. B. and Oakeshott, J. G. (eds) Genetic Studies of Drosophila Populations Australian National University, Canberra, pp. 47-57.

ROUAULT, J. AND DAVID, J. R. 1982. Evolutionary biology of Drosophila melanogaster and D. simulans: a behavioural divergence in microhabitat selection. Acta. Oecologica / Oecologia Generalis, 3, 331-338.

SCHWARTZ, M. AND SOFER, W. 1976. Diet-induced alterations in distribution of multiple forms of alcohol dehydrogenase in Drosophila. Nature, 263, 129-131. 
THOMPSON, J. N. AND KAISER, T. N. 1977. Selection acting upon slow-migrating ADH alleles differing in enzyme activity. Heredity, 38, 191-195.

VAN DELDEN, W. 1983. The alcohol dehydrogenase polymorphism in Drosophila melanogaster. Evol. Biol., 15, 187 222.

WILKS, A. V., GIBSON, J. B., OAKESHOTT, J. G. AND CHAMBERS, G. K. 1980. An electrophoretically cryptic alcohol dehydrogenase variant in Drosophila melanogaster: II. Postelectrophoresis heat-treatment screening of natural populations. Aust. J. Biol. Sci., 33, 575-585.
WARD, R. D. AND HEBERT, P. D. N. 1972. Variability of alcohol dehydrogenase activity in a natural population of Drosophila melanogaster. Nature, 236, 243-244.

ZERA, A. J., KOEHN, R. K. AND HALl, J. G. 1983. Allozymes and biochemical adaptation. In Kerkut, G. A. and Gilbert, L. I. (eds) Comprehensive Insect Physiology, Biochemistry and Pharmacology, vol. 10, Pergamon Press, New York, pp. 633-675.

ZIOLA L. K. AND PARSONS, P. A. 1982. Ethanol tolerance, alcohol dehydrogenase activity and $A d h$ allozymes in Drosophila melanogaster. Genetica, 57, 231-237. 